\title{
Application of Intervention Analysis Model in Yu Ebao Yield Prediction
}

\author{
Jian Su, Guangming Deng \\ College of Science, Guilin University of Technology, Guilin, China \\ Email: sujian2233@163.com \\ Received 20 May 2014; revised 9 June 2014; accepted 5 July 2014 \\ Copyright (C) 2014 by authors and Scientific Research Publishing Inc. \\ This work is licensed under the Creative Commons Attribution International License (CC BY). \\ http://creativecommons.org/licenses/by/4.0/

c) (i) Open Access

\begin{abstract}
This paper used the intervention analysis model to fit the data of seven-day annualized yield of Yu Ebao, by regarding the Niu's comment as intervention. We constructed the linear model and the intervention model. The result showed that though Niu's comment was not the most important cause of the decline of the yield, its effects cannot be ignored. And it caused the yield of Yu Ebao fallen $0.148 \%$ faster than before.
\end{abstract}

\section{Keywords}

Yu Ebao, Yield, Intervention Analysis Model

\section{Introduction}

Recently, a series of internet financial products were launched by many internet companies and fund management companies, which attracted a lot of investors' attention. Yu Ebao is one of these products. Yu Ebao was a balance value-added service built by the third party payment platform Alipay, which was launched in June 13, 2013. Essentially, it is a monetary fund launched by the Alipay cooperated with the Tianhong Asset Management Company. The users will access certain benefits by transferring the money to Yu Ebao. Due to that fact that its yield was higher than the bank current deposit interest rate, and the account funds could be used for online shopping or transferring at any time, it attracted a large number of young people fascinated in online shopping. As of February 27, 2014, Yu Ebao user amount has exceeded 81 million, and its asset size was larger than 5 hundred billion.

The yield of Yu Ebao was increased steadily since its launch (Figure 1), even broke through 6.7\%, and lasted for 10 days long. However, nothing gold can stay, at the beginning of 2014, major banks had teamed up with other fund companies to launch their own internet financial products. Besides, under the pressure of other like products which came from Baidu and Jingdong companies, the yield of Yu Ebao was all the way down after the 


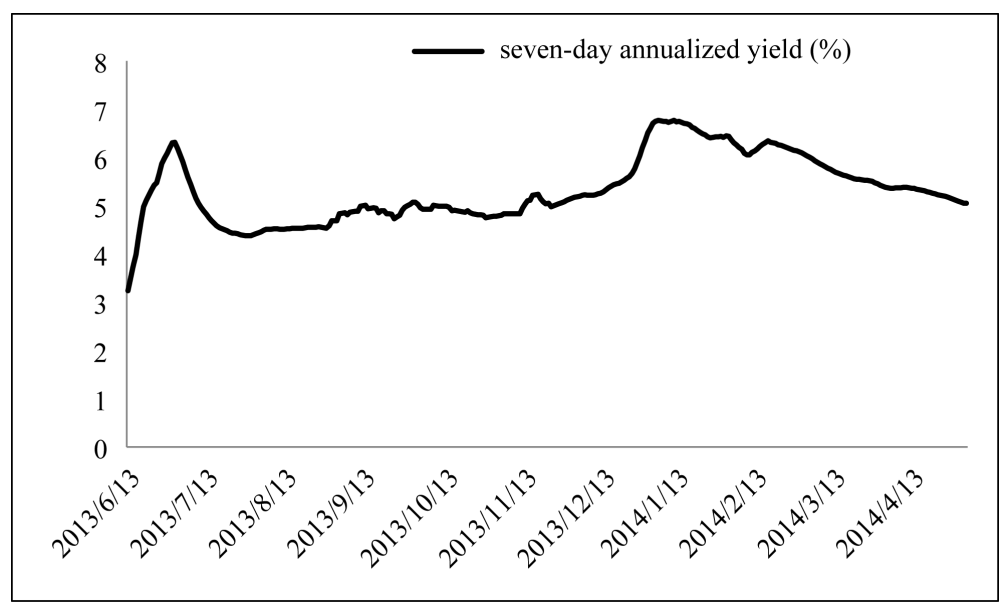

Figure 1. The seven-day annualized yield of Yu Ebao.

peak.

On the day of February 21, 2014, Wenxin Niu whom is the chief executive editor and chief commentator of CCTV security information channel, accused that Yu Ebao was a "vampire” lying on the bank, a typical "financial parasite”, and advocated to ban this product. Niu’s comment was reported by many authoritative media, and sent shock waves throughout the internet. Because of this, the yield of Yu Ebao fallen sharply. Even though on March 4, Xiaochuan Zhou, president of the people's bank of China, indicated that they won't ban the Yu Ebao, that's unable to block the yield decline. Based on the background above, we regarded Niu's comment as the intervention, applying the intervention analysis model to analyze and predict the trend of seven-day annualized yield, quantitatively studying its running track.

\section{Intervention Analysis Model}

The intervention analysis model is proposed by Box and Tiao, professors of University of Wisconsin, department of statistics [1]. Intervention analysis is to evaluate the impacts of policy events or emergency on the economic environment and process from the angle of quantitative analysis [2]. The intervention parameters fall into two categories, continuous and transitory. The continuous parameter refers that the intervention event still affects the changes after the moment $T$. The basic variable of intervention analysis model is the intervention variable, i.e.

$$
S_{t}^{T}= \begin{cases}0, & \text { before the intervention }(t<T) \\ 1, & \text { after the intervention }(t \geq T)\end{cases}
$$

The intervention model is $Z_{t}=\frac{\omega}{1-\delta B} S_{t}^{T}$, where $\omega$ represents the unknown parameter of the intervention effect strength, $\delta$ represents the intervention duration, $B$ is delay operator.

Four kinds of intervention type concluded as below:

1) The influence of intervention appears all of a sudden, and continues for a long time;

2) The influence of intervention appears gradually, and continues for a long time;

3) The intervention occurs suddenly, and the influence is temporary;

4) The intervention occurs gradually, and the influence is temporary.

There are four steps to modeling the intervention analysis model. First of all, we construct a univariate time series model by using the data before intervention, then applying the model to make the prediction, the prediction data we get is without intervention. Secondly, with the real value minus the predicted value, the difference is the intervention value. Then we estimate the parameter of the intervention model. Thirdly, we combine the real data before the intervention and the prediction data which came from the intervention model as a complete data. Then we construct another univariate time series model. At last, with the last univariate time series model and the intervention model, the combination is the final intervention analysis model. 


\section{Data Analysis}

\subsection{Data Specification}

This paper uses the seven-day annualized yield of Yu Ebao from January 1 to April 30, 2014 as data. The data is collected from the official website of the Tianhong Asset Management Company (http://www.thfund.com.cn). The data is shown in the Appendix.

\subsection{Model Construction before the Intervention}

According to the observation of the data before the intervention (before February 21), and the comparison of several models fitted effect, we chose the linear model. The model we constructed is:

$$
\hat{x}_{0 t}=6.774-0.013 t
$$

where the model goodness of fit $R^{2}=0.807$, model $F$ Test $F=217.787(P=0.000)$, and all the parameters in the model is significant under the significant level 0.05 , all of these show that the model fitting effect is great.

\subsection{Intervention Model Construction}

With the linear model we got above, we predict the yield $\hat{x}_{0 t}$ from February 21 to April 30. Then we compute the intervention effect value $Z_{t}=x_{t}-\hat{x}_{0 t}, Z_{t}$ is the quantitative impact value of Niu's comment on Yu Ebao's yield. We estimate the parameters of the intervention model and get this:

$$
Z_{t}=-\frac{0.014}{1-0.928 B}
$$

where the model goodness of fit $R^{2}=0.985$, model $F$ Test $F=4108.933(P=0.000)$, and all the parameters in the model is significant under the significant level 0.05 , all of these show that the model fitting is great.

\subsection{Purified Series Model Construction}

The purified series refer to the series without the intervention impact, i.e. $y_{t}=x_{t}-\frac{\omega}{1-\delta B} S_{t}^{T}$ $(T=51, t=1,2, \cdots, 120)$. We still chose the linear model to fit the purified series, the result is:

$$
\hat{y}_{t}=6.774-0.013 t
$$

where the model goodness of fit $R^{2}=0.979$, model $F$ Test $F=5377.901(P=0.000)$, and all the parameters in the model is significant5, all of these show that the model fitting is great.

\subsection{The Final Intervention Analysis Model}

Combining the intervention model and the purified series model, we get the final intervention analysis model:

$$
\begin{gathered}
x_{t}=6.774-0.013 t+\frac{-0.014}{1-0.928 B} S_{t}^{T} \\
S_{t}^{T}= \begin{cases}0, & \text { before February } 21,2014(t<51) \\
1, & \text { February 21, } 2014 \text { and after }(t \geq 51)\end{cases}
\end{gathered}
$$

By comparing the prediction value of intervention analysis model and the raw data (Figure 2), we know that the two series are highly consistent, which shows that the model we constructed is reasonable.

According to the analysis above, we conclude that Niu's comment made the yield fallen faster and faster, the average impact is $-0.148 \%$, i.e. after the comment, the yield of Yu Ebao fallen $0.148 \%$ faster than before.

\section{Conclusion and Improvement}

There are a lot of factors affecting the financial product yield [3]. The direct factors include national polity, rate changing, the company's own development, etc. The indirect factors include economic environment, comment, especially the famous scholars' comment, which will first affect the investors' psychology. Then the investors 


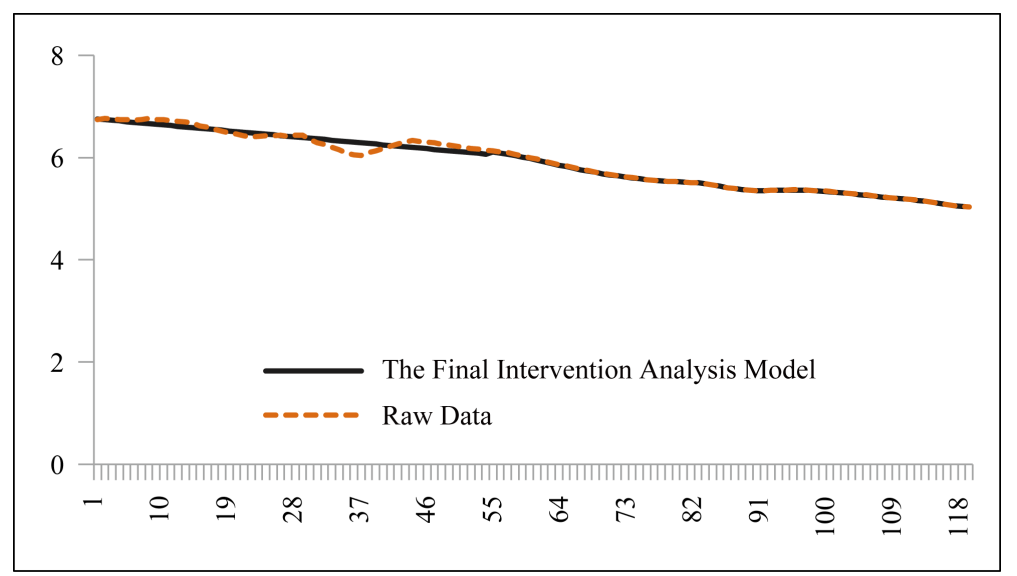

Figure 2. Intervention analysis model prediction effect.

will make their own choices to enter or exit the market according to the good or bad news; what's more, that will affect yield of the product. Through the intervention analysis model, we fitted the impact of "ban Yu Ebao" comment on its yield accurately.

Yu Ebao as a monetary fund product, is restricted by the deposit rate of the bank, so that its yield won't never keep on the high level [4]. Dengfeng Wang, fund manager of the Tianhong asset management company, explained that the reason why the yield was so high is that the money is in short supply at the end of the year and before the Spring Festival, so the investors who invest the monetary fund enjoyed a higher income. But after the Spring Festival, the money supply tension reduced, the yield of Yu Ebao is returned to the normal level. Therefore, though Niu's comment was not the most important cause of the decline of the yield, with the analysis above, its effects cannot be ignored [5].

This paper only considered the linear and curve regression model when we constructed the model. We haven't considered applying some general time series model, such as ARIMA model, ARCH model, etc. So in the future research work, we will apply more types of model and compare their fitting effect.

\section{Acknowledgements}

This work was jointly supported by the National Social Science Fund (No. 13BTJ009).

\section{References}

[1] Box, G.E.P. and Tiao, G.C. (1975) Intervention Analysis with Applications to Economic and Environmental Problems. Journal of the American Statistical Association, 70, 70-79. http://dx.doi.org/10.1080/01621459.1975.10480264

[2] Xu, G. (2008) Statistical Forecasting and Decision-Making. 3rd Edition, Shanghai University of Finance \& Economics Press Co., LTD., Shanghai.

[3] Fan, M. (2013) The Trend, Influence and Policy Suggestion of “Yu Ebao” Business. Times Finance, 528, 138-139.

[4] Li, Q.Y. (2013) Yu Ebao: The High Yield Will Not Be Lasted. Finance \& Accounting, 11, 72.

[5] Chen, C. (2014) The Economic Foundation of the High Yield of Yu Ebao. Times Finance, 546, 63. 
Appendix

\begin{tabular}{|c|c|c|c|c|c|}
\hline Date & Yield (\%) & Date & Yield (\%) & Date & Yield (\%) \\
\hline $2014 / 1 / 1$ & 6.74 & $2014 / 2 / 10$ & 6.225 & $2014 / 3 / 22$ & 5.526 \\
\hline $2014 / 1 / 2$ & 6.763 & $2014 / 2 / 11$ & 6.263 & $2014 / 3 / 23$ & 5.516 \\
\hline $2014 / 1 / 3$ & 6.753 & $2014 / 2 / 12$ & 6.298 & $2014 / 3 / 24$ & 5.511 \\
\hline $2014 / 1 / 4$ & 6.745 & $2014 / 2 / 13$ & 6.334 & $2014 / 3 / 25$ & 5.496 \\
\hline $2014 / 1 / 5$ & 6.738 & $2014 / 2 / 14$ & 6.311 & $2014 / 3 / 26$ & 5.472 \\
\hline $2014 / 1 / 6$ & 6.726 & $2014 / 2 / 15$ & 6.298 & $2014 / 3 / 27$ & 5.445 \\
\hline $2014 / 1 / 7$ & 6.738 & $2014 / 2 / 16$ & 6.286 & $2014 / 3 / 28$ & 5.415 \\
\hline $2014 / 1 / 8$ & 6.761 & $2014 / 2 / 17$ & 6.259 & $2014 / 3 / 29$ & 5.395 \\
\hline $2014 / 1 / 9$ & 6.737 & $2014 / 2 / 18$ & 6.241 & $2014 / 3 / 30$ & 5.374 \\
\hline $2014 / 1 / 10$ & 6.738 & $2014 / 2 / 19$ & 6.22 & $2014 / 3 / 31$ & 5.361 \\
\hline $2014 / 1 / 11$ & 6.721 & $2014 / 2 / 20$ & 6.201 & $2014 / 4 / 1$ & 5.356 \\
\hline 2014/1/12 & 6.703 & $2014 / 2 / 21$ & 6.183 & $2014 / 4 / 2$ & 5.357 \\
\hline 2014/1/13 & 6.695 & $2014 / 2 / 22$ & 6.165 & $2014 / 4 / 3$ & 5.362 \\
\hline $2014 / 1 / 14$ & 6.67 & $2014 / 2 / 23$ & 6.147 & $2014 / 4 / 4$ & 5.367 \\
\hline 2014/1/15 & 6.618 & $2014 / 2 / 24$ & 6.136 & $2014 / 4 / 5$ & 5.37 \\
\hline 2014/1/16 & 6.595 & $2014 / 2 / 25$ & 6.114 & $2014 / 4 / 6$ & 5.373 \\
\hline 2014/1/17 & 6.554 & $2014 / 2 / 26$ & 6.093 & $2014 / 4 / 7$ & 5.373 \\
\hline 2014/1/18 & 6.517 & $2014 / 2 / 27$ & 6.062 & $2014 / 4 / 8$ & 5.368 \\
\hline 2014/1/19 & 6.48 & $2014 / 2 / 28$ & 6.031 & $2014 / 4 / 9$ & 5.36 \\
\hline $2014 / 1 / 20$ & 6.46 & $2014 / 3 / 1$ & 6.001 & $2014 / 4 / 10$ & 5.351 \\
\hline $2014 / 1 / 21$ & 6.423 & $2014 / 3 / 2$ & 5.971 & $2014 / 4 / 11$ & 5.339 \\
\hline $2014 / 1 / 22$ & 6.398 & $2014 / 3 / 3$ & 5.928 & $2014 / 4 / 12$ & 5.327 \\
\hline $2014 / 1 / 23$ & 6.413 & $2014 / 3 / 4$ & 5.895 & $2014 / 4 / 13$ & 5.315 \\
\hline $2014 / 1 / 24$ & 6.422 & $2014 / 3 / 5$ & 5.864 & $2014 / 4 / 14$ & 5.3 \\
\hline $2014 / 1 / 25$ & 6.424 & $2014 / 3 / 6$ & 5.835 & $2014 / 4 / 15$ & 5.287 \\
\hline $2014 / 1 / 26$ & 6.434 & $2014 / 3 / 7$ & 5.805 & $2014 / 4 / 16$ & 5.272 \\
\hline $2014 / 1 / 27$ & 6.416 & $2014 / 3 / 8$ & 5.774 & $2014 / 4 / 17$ & 5.253 \\
\hline $2014 / 1 / 28$ & 6.441 & 2014/3/9 & 5.744 & $2014 / 4 / 18$ & 5.239 \\
\hline $2014 / 1 / 29$ & 6.432 & $2014 / 3 / 10$ & 5.716 & $2014 / 4 / 19$ & 5.224 \\
\hline 2014/1/30 & 6.36 & $2014 / 3 / 11$ & 5.69 & $2014 / 4 / 20$ & 5.21 \\
\hline 2014/1/31 & 6.293 & $2014 / 3 / 12$ & 5.668 & $2014 / 4 / 21$ & 5.2 \\
\hline $2014 / 2 / 1$ & 6.253 & $2014 / 3 / 13$ & 5.647 & $2014 / 4 / 22$ & 5.188 \\
\hline $2014 / 2 / 2$ & 6.205 & $2014 / 3 / 14$ & 5.628 & $2014 / 4 / 23$ & 5.171 \\
\hline $2014 / 2 / 3$ & 6.158 & $2014 / 3 / 15$ & 5.61 & $2014 / 4 / 24$ & 5.152 \\
\hline $2014 / 2 / 4$ & 6.085 & $2014 / 3 / 16$ & 5.592 & $2014 / 4 / 25$ & 5.13 \\
\hline $2014 / 2 / 5$ & 6.051 & $2014 / 3 / 17$ & 5.568 & $2014 / 4 / 26$ & 5.109 \\
\hline $2014 / 2 / 6$ & 6.044 & $2014 / 3 / 18$ & 5.555 & $2014 / 4 / 27$ & 5.087 \\
\hline $2014 / 2 / 7$ & 6.096 & 2014/3/19 & 5.544 & $2014 / 4 / 28$ & 5.067 \\
\hline $2014 / 2 / 8$ & 6.135 & $2014 / 3 / 20$ & 5.538 & $2014 / 4 / 29$ & 5.048 \\
\hline $2014 / 2 / 9$ & 6.174 & $2014 / 3 / 21$ & 5.535 & $2014 / 4 / 30$ & 5.04 \\
\hline
\end{tabular}


Scientific Research Publishing (SCIRP) is one of the largest Open Access journal publishers. It is currently publishing more than 200 open access, online, peer-reviewed journals covering a wide range of academic disciplines. SCIRP serves the worldwide academic communities and contributes to the progress and application of science with its publication.

Other selected journals from SCIRP are listed as below. Submit your manuscript to us via either submit@scirp.org or Online Submission Portal.
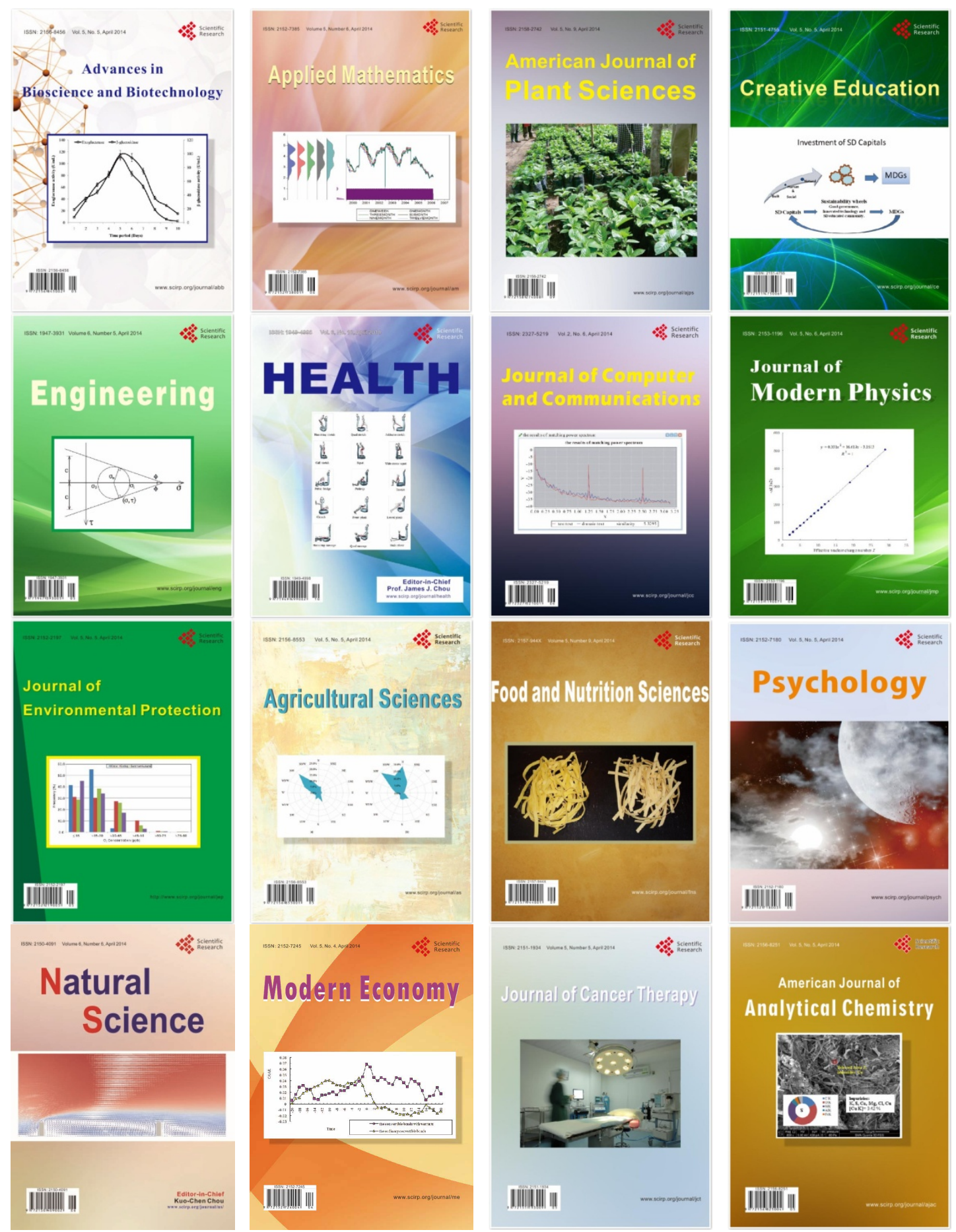